\title{
A GM(1,N) Approach to the Pricing of Auto Production in China
}

\author{
Wang Zhaoyan * \\ School of Economics and Management, Nanjing University of Science and Technology, Nanjing \\ 210094, China \\ zywang_2014@163.com
}

Keywords: auto production; pricing method; grey correlation analysis; $\mathrm{GM}(1, \mathrm{~N})$ model.

Abstract. The study of pricing method of auto production has very important significance to analyze auto market and make strategic decision. The paper considers the current research status of pricing method of auto production, analysis the factors which influence the price of auto production, and proposes $\mathrm{GM}(1, \mathrm{~N})$ model to the pricing of auto production in china. Through empirical research, we can find that this method can effectively use the limited data to construct the pricing model of auto production and is more exact than traditional method.

\section{Introduction}

In the last ten years, the auto production market in china has become a multi-level and multi-discipline market system., Since the financial crisis has prompted market adjustment in 2009, the auto production market in china presents unprecedented development trend in particular. In 2014, the auto sales in china were 23.49 million and ranked first in the world in the last six years [1]. Price is not only the basic communication between buyer and seller but also the important means of realizing the enterprise strategy. A reasonable and effective pricing method of auto production is of great significance for the auto enterprise development.

At present, the pricing method of auto production mainly has the following several methods [2]: 1) The analogy method. It determines the price interval by referring the same production sold prices; 2) The equilibrium price method. It uses the theory of equilibrium price to study the pricing mechanism of auto production and analyze the factors that affect the supply and demand of auto production to determine the auto price. 3) The hedonic method. Luan studied the price strategy of auto production in china by using the hedonic method [3]. The price model of auto characteristic was fitted by the analysis of the relationship between the factors and the price. Although the characteristic price index method has many advantages, it has some own disadvantages [4-6]: (1) The method needs a lot of price data and has to quantify the characteristics of each feature. (2) Some implicit feature variables are often neglected, and even cannot be predicted; (3) Due to the market environment often change, the time coefficients of regression equation often change.

These methods are not applicable to auto market in china, mainly because that the following three aspects are not considered in these methods. First, the data sample is less. Since the auto market in china has a short development time, the reference data of similar works with the same brand is limited. Second, the influence factors include both quantitative and qualitative factors. Lastly, the relationship between multiple factors and auto price is uncertain because of the limited data information. Therefore, it is an urgent problem how to analyze and utilize the limited data information to construct the pricing model of auto production in china.

The grey system theory is a new method to study the problem that less data and information. The grey system theory takes the uncertain system with "little sample" and "poor information" as the research object. It realized the correct description and effective monitoring of the system's operational behavior and the evolution of the rules by extraction of the valuable information from the "little sample" and "poor information" [7]. The analysis method of the grey correlation degree is a quantitative description and comparison method for the development of a system. The basic idea is to determine whether the reference data is closely related to some comparative data by the level of similarity. Through the analysis of the gray correlation degree, we can get the incidence relation 
between the variables. GM $(1, \mathrm{~N})$ model is established by differential fitting method base on the gray model. The model has the advantages of less data and can effectively take into account the uncertainty of the model. It is widely used to analyze the correlation between multiple input factors and forecast the short-term outlook of the output factors of the system [8-9].

In view of the characteristics of auto market in china, this paper studied the pricing of auto production in china and proposed $\operatorname{GM}(1, N)$ model to the pricing of auto production. The grey correlation degree method is used to analyze the gray correlation degree of each factor, and the GM (1, $\mathrm{N}$ ) model is used to construct the pricing model of auto production in china. Through the research on the price of auto production, the GM $(1, \mathrm{~N})$ model is a good model to deal with the problem that poor data and information. It can effectively estimate the auto production price and solve the pricing problem of auto production market in china.

\section{The Proposed Method}

\section{Analysis of influence factors}

The Grey correlation reflects the correlation degree of the curves. There are three expressions that slope correlation degree, relative rate correlation degree and area correlation degree. The slope correlation degree can handle the negative or zero value problems in processing data. The paper applied the slope correlation degree to calculate the relationship between the influence factors and the auto prices. The steps as follows:

Assume the data sequence of the $i$ th influence factor is $\left\{x_{i}^{(0)}(k)\right\}$ and the data sequence of the price is $\left\{y^{(0)}(k)\right\}$ with $i=1,3, \ldots, n, k=1, \ldots . m$.

(1) The slope of influence factors and prices

The calculation formulas for the slope of influence factors and prices are as follows:

$$
\begin{aligned}
& \frac{\Delta x_{i}^{(0)}(k)}{\sigma_{x_{i}^{(0)}}}=\left[x_{i}^{(0)}(k+1)-x_{i}^{(0)}(k)\right] / \sigma_{x_{i}^{(0)}}, i=1, \mathrm{~L}, n, k=1, \mathrm{~L}, m \\
& \frac{\Delta y^{(0)}(k)}{\sigma_{y^{(0)}}}=\left[y_{i}^{(0)}(k+1)-y^{(0)}(k)\right] / \sigma_{y^{(0)}}, i=1, \mathrm{~L}, n, k=1, \mathrm{~L}, m
\end{aligned}
$$

with $m$ is the sample size; $n$ is the variable number; $\sigma_{x_{i}^{(0)}}$ is the standard deviation of the input $x_{i}^{(0)} ; \sigma_{y^{(0)}}$ is the standard deviation of the output $y^{(0)}$.

(2) The calculation of correlation coefficient

The correlation coefficient compared the correlation degree between the data and standard data. The correlation coefficient of the series of the influence factors $\left\{x_{i}^{(0)}(k)\right\}$ and the prices $\left\{y^{(0)}(k)\right\}$ can be calculated by eq. (3)

$$
\zeta_{x_{i}^{(0)} y^{(0)}}(k)=1 /\left[1+\left|\frac{\Delta y^{(0)}(k)}{\sigma_{y^{(0)}}}-\frac{\Delta x_{i}^{(0)}(k)}{\sigma_{x_{i}^{(0)}}}\right|\right], i=1,2, \mathrm{~L}, n, k=1,2, \mathrm{~L}, m
$$

(3) The correlation degree and correlation order

Since the information is too scattered to compare integrity, the correlation coefficient of each moment must be focused to a value, which as the correlation degree between $\left\{x_{i}^{(0)}(k)\right\}$ and $\left\{y^{(0)}(k)\right\}$. The correlation degree $\gamma_{x_{i}^{(0)} y^{(0)}}$ can be calculated by the following eq.(4).

$$
\gamma_{x_{i}^{(0)} y^{(0)}}=\frac{1}{m-1} \sum_{k=1}^{m} \zeta_{x_{i}^{(0)} y^{(0)}}(k), i=1,2, \mathrm{~L}, n, k=1,2, \mathrm{~L}, m
$$

According to the magnitude of $\gamma_{x_{i}^{(0)} y^{(0)}}$, the arrangement of correlation order can be realized, which can realize the choice of the significant variables. 


\section{Price model of auto production based on the GM(1,N) model}

The grey $\operatorname{GM}(1, N)$ model analyzed the operation structure of the system and predicted the change trend of the production price by study the dynamic correlation between the influence factors and auto production prices. The first-order accumulative generation sequence of the $i$ th influence $x_{i}^{(0)}(k)$ and production price $y_{i}^{(0)}(k)$ are

$$
\begin{aligned}
& x_{i}^{(1)}(k)=\sum_{j=1}^{k} x_{i}^{(0)}(j), i=1,2, \ldots, n \\
& y_{i}^{(1)}(k)=\sum_{j=1}^{k} y_{i}^{(0)}(j), i=1,2, \ldots, n
\end{aligned}
$$

So the grey differential equation of $\operatorname{GM}(1, N)$ model is

$$
y^{(0)}(k)+a z^{(1)}(k)=b_{1} x_{1}^{(1)}(k)+b_{2} x_{2}^{(1)}(k)+\ldots+b_{N} x_{N}^{(1)}(k), k=1,2, \mathrm{~L}, m
$$

with $z^{(1)}(k)=\frac{y^{(1)}(k)+y^{(1)}(k-1)}{2}, a$ is the system development coefficient, $b_{i}$ is the system grey coefficient or harmonious development coefficient. The response winterization equation of eq.(7) is

$$
\frac{d y^{(1)}(k)}{d t}+a y^{(1)}(k)=b_{1} x_{1}^{(1)}(k)+b_{2} x_{2}^{(1)}(k)+\ldots+b_{N} x_{N}^{(1)}(k)
$$

and the solution of winterization eq.(8) is

$$
y^{(1)}(k)=e^{-a k}\left(y^{(1)}(0)-k \sum_{i=1}^{N} b_{i} x_{i}^{(1)}(0)+\sum_{i=1}^{N} \int b_{i} x_{i}^{(1)}(t) e^{a k} d k\right)
$$

If the sequence data of the influence factors $\left\{x_{i}^{(0)}(k)\right\}(i=1,2, \ldots, N)$ have a little change in the time sequence $\left[t_{k}, t_{k+1}\right]$, the approximate response equation of the grey differential eq.(7) is

$$
\hat{y}^{(1)}(k+1)=\left(y^{(1)}(0)-\frac{1}{a} \sum_{i=1}^{N} b_{i} x_{i}^{(1)}(k+1)\right) e^{-a k}+\frac{1}{a} \sum_{i=1}^{N} b_{i} x_{i}^{(1)}(k+1)
$$

with $y^{(1)}(0)=y^{(0)}(1), \hat{a}=\left(a, b_{2}, b_{3}, \ldots, b_{N}\right)^{T}=\left(B^{T} B\right)^{-1} B^{T} Y$, the matrix $B$ and vector $Y$ are

$$
B=\left[\begin{array}{cccc}
-z^{(1)}(2) & x_{1}^{(1)}(2) & \ldots & x_{N}^{(1)}(2) \\
-z^{(1)}(3) & x_{1}^{(1)}(3) & \ldots & x_{N}^{(1)}(3) \\
\ldots & \ldots & \ldots & \ldots \\
-z^{(1)}(n) & x_{1}^{(1)}(n) & \ldots & x_{N}^{(1)}(n)
\end{array}\right], Y=\left[\begin{array}{c}
y^{(0)}(2) \\
y^{(0)}(3) \\
\ldots \\
y^{(0)}(n)
\end{array}\right]
$$

According the eq.(6) and eq.(10), we can obtain the following equation:

$$
\hat{y}^{(0)}(k+1)=\hat{y}^{(1)}(k+1)-\hat{y}^{(1)}(k)
$$

The fitting precision of model (4) can be checked by analysis the error $\varepsilon(k)$ and average relative error $e_{r}$ of the estimates of the price. The error $\varepsilon(k)$ and average relative error $e_{r}$ can be expressed as:

$$
\varepsilon(k)=\hat{y}^{(0)}(k)-y^{(0)}(k)
$$




$$
e_{r}=\frac{1}{m} \sum_{k=1}^{m} \frac{|\varepsilon(k)|}{\left|y^{(0)}(k)\right|}
$$

\section{The proposed algorithm for pricing of auto production}

The paper proposed the pricing method of the auto production in china based on the $\mathrm{GM}(1, \mathrm{~N})$ model. The specific steps are as follows:

Step1: Collect and filter the data of auto production prices and influence factors with consideration the accuracy of the collected data.

Step2: Analyze the influence factors of auto production prices and divide the influence factors into quantitative and qualitative factors.

Step3: Calculate the grey correlation degree of each influence factor and auto production price and arrange the correlation order.

Step4: Construct the auto production price model based on $\operatorname{GM}(1, N)$ and analyze the relative error when choose different influence factor. The model with better fitting and reliability can be obtained by selected the lowest relative error.

\section{Empirical Evaluation}

\section{Data collection and factor analysis}

The Shanghai Volkswagen auto production were chosen as an example to illustrate the effective of the proposed method. The collected data come from the professional auto website. Comfortable, economy, security and operability are the four factors that must be considered when consumers purchase a car. Therefore, the choice of car characteristics mainly from these four aspects and the selected variables can reflect the consumer's concept as possible as possible. At the same time, this research has referred to the opinions of the experts and divides the factors into quantitative and qualitative factors. The selected factors are shown in Table 1, where the quantitative factors are represented by the code $x_{i}(i=1,2,3 \mathrm{~L})$, and the qualitative factors are represented by $d_{j}(j=1,2,3 \mathrm{~L})$.

\section{Data analysis and comparison}

The price modeling and analysis of auto production of Shanghai Volkswagen are carried out by using the proposed method in this paper. According to the order from big to small of gray correlation degree of each influence factor, the top ten influence factors in correlation degree are shown in the Table 2.

From the table 2, it can be clearly shown that the largest influence factor of grey correlation degree is the weight $\left(x_{10}\right)$. According to the order from big to small of gray correlation degree, the ten order is obtained: $x_{10}, x_{15}, x_{6}, x_{12}, x_{3}, x_{14}, d_{13}, d_{14}, d_{3} . x_{1}$ 。

According to the gray correlation order, the price model is constructed by the selection of different influence factors, and the relative error and relative error of different productions are calculated to determine the optimal number of factors and the optimal GM $(1, \mathrm{~N})$. As shown in the Table 3, the relative error of the range is only between $0.7 \%$ to $4.7 \%$ when the model is constructed by the selection of the first 2 to 5 factors. When the model is constructed by the selection of the the first 6 factors, the relative error of the model is increased to $23.3033 \%$. Therefore, the GM $(1,5)$ model has a strong fitting degree and reliability.

To illustrate the effective of the proposed method, the paper compares it with the double logarithmic Hedonic model in the paper [3,4]. Through testing the goodness of fit of the fitted $\operatorname{GM}(1,5)$ model and the double logarithmic Hedonic model, we can obtain that the goodness of fit of GM $(1,5)$ model is 0.92, while the double logarithmic Hedonic model is 0.80. Obviously, the GM $(1,5)$ model is better than the double logarithmic Hedonic model, which means that the proposed method can effectively improve the model accuracy and is easy to analyze the impact factors on the production pricing. 
Table1 The influence factors of auto production price

\begin{tabular}{|c|c|c|}
\hline \multirow{2}{*}{ Category } & \multicolumn{2}{|l|}{ Influence factors } \\
\hline & Index & Code \\
\hline \multirow{13}{*}{ Comfortable } & Length & $x_{1}$ \\
\hline & Height & $x_{2}$ \\
\hline & Width & $x_{3}$ \\
\hline & The luggage compartment volume & $x_{4}$ \\
\hline & Wheelbase & $x_{5}$ \\
\hline & Track front & $x_{6}$ \\
\hline & Track rear & $x_{7}$ \\
\hline & EBD & $d_{1}$ \\
\hline & Electrical power steering & $d_{2}$ \\
\hline & Automatic constant temperature air conditioning system & $d_{3}$ \\
\hline & Induction of rainfall wiper & $d_{4}$ \\
\hline & If there is $\mathrm{CD}$ & $d_{5}$ \\
\hline & If there is VCD & $d_{6}$ \\
\hline \multirow{3}{*}{ Economy } & Fuel consumption & $x_{8}$ \\
\hline & Delivery capacity & $x_{9}$ \\
\hline & Weight & $x_{10}$ \\
\hline \multirow{6}{*}{ Security } & ABS system & $d_{7}$ \\
\hline & The car central lock & $d_{8}$ \\
\hline & Engine electronic guard against theft & $d_{9}$ \\
\hline & Burglar alarm & $d_{10}$ \\
\hline & Child safety lock & $d_{11}$ \\
\hline & Gasbag & $d_{12}$ \\
\hline \multirow{8}{*}{ Operability } & Fuel tank capacity & $x_{11}$ \\
\hline & Maximum speed & $x_{12}$ \\
\hline & Air cylinder & $x_{13}$ \\
\hline & Maximum power & $x_{14}$ \\
\hline & Maximum Torque & $x_{15}$ \\
\hline & Hundred kilometers acceleration time & $x_{16}$ \\
\hline & If there is turbocharging & $d_{13}$ \\
\hline & If there is DSG & $d_{14}$ \\
\hline
\end{tabular}

Table 2 The top ten factors in correlation degree

\begin{tabular}{ccccccccccc}
\hline Influence factors & $x_{10}$ & $x_{15}$ & $x_{6}$ & $x_{12}$ & $x_{3}$ & $x_{14}$ & $d_{13}$ & $d_{14}$ & $d_{3}$ & $x_{1}$ \\
\hline Correlation degree & 0.8860 & 0.7707 & 0.7282 & 0.6945 & 0.6882 & 0.6014 & 0.5584 & 0.5584 & 0.5584 & 0.5466 \\
\hline
\end{tabular}

Table 3 The relative error of different factor of Shanghai Volkswagen auto

\begin{tabular}{cccccc}
\hline \multirow{2}{*}{ Vaiable number } & \multicolumn{4}{c}{ Productions } & \multirow{2}{*}{ Range } \\
\cline { 2 - 5 } & Production2 & Production 3 & Production 4 & Production 5 & \\
\hline 2 & -1.1416 & 0.2274 & 0.0740 & 0.5990 & 1.7406 \\
3 & -0.3821 & -0.0454 & 0.3360 & -0.1034 & 0.7181 \\
4 & -1.7994 & -0.3508 & 1.4093 & -0.5654 & 3.2087 \\
5 & -2.6255 & -0.5094 & 2.0595 & -0.8236 & 4.6850 \\
6 & -12.116 & -1.0145 & 11.1917 & -3.0332 & 23.3033 \\
7 & -12.1430 & -1.0118 & 11.2275 & -3.0380 & 23.3705 \\
8 & -12.1742 & -1.0091 & 11.2631 & -3.0428 & 23.4373 \\
9 & -12.2055 & -1.0063 & 11.2988 & -3.0476 & 23.5043 \\
10 & -15.1212 & -0.6204 & 14.7912 & -3.4162 & 29.9124 \\
\hline
\end{tabular}




\section{Summary}

This paper analyzes the pricing problem of auto production market in china, and proposes $\operatorname{GM}(1, \mathrm{~N})$ model to the pricing of auto production. Through empirical research, we can find that this method can effectively analyze and use the limited data to construct the pricing model of auto production and is more exact than traditional method. For the pricing of auto production in china, this method has very important guiding significance.

\section{Acknowledgements}

This work is supported by the the National Natural Science Foundation of China (No. 71301075) and the National Natural Science Foundation of Jiangsu Province in China (No. BK20130770). The author thanks Dr Sheng Wang for his kind help during all phases of the research work.

\section{References}

[1] China association of automobile manufacturers, The automobile industry development report Blue Book: annual China automobile industry, Social sciences academic press(China), Beijing, 2015.

[2] C M Ge, The pricing of auto production in china, Jilin University, 2008.

[3] Z Q Luan, The research on automobile pricing strategy based on hedonic price model, China University of Mining and Technology, 2009.

[4] L Renneboog, C Spaenjers, Buying beauty: On prices and returns in the art market, Management Science. 59(2013)36-53.

[5] B T Celia, C F Verónica, The price of secondary school quality: a hedonic approach, Applied Economics Letters. 20(2013)706-709.

[6] B Jasper, B Pascal, D K Erwin, M Karel, A hedonic price analysis of the value of industrial sites, Journal of Property Research. 31(2014)108-130.

[7] M X He, Q Wang, New algorithm for GM(1,N) modeling based on simpson formula, Systems Engineering-Theory \& Practice. 33(2013)199-202.

[8] S J Yin, L H Wu, Y Zhang, Empirical analysis of the factors influencing grain yield, Systems Engineering-Theory \& Practice. 29(2009)28-34.

[9] J Wang, S Liu, Prediction of efficient outputs based on $\operatorname{GM}(1, \mathrm{~N})$ model and weak DEA efficiency, Journal of Systems Engineering and Electronics. 22(2011)933-939. 